\title{
Urban Heat in the Anthropocene: Coming Soon to Your City
}

\author{
Doug Kelbaugh Faia
}

College of Architecture and Urban Planning, University of Michigan, USA

Copyright $\bigcirc 2019$ by authors, all rights reserved. Authors agree that this article remains permanently open access under the terms of the Creative Commons Attribution License 4.0 International License

\begin{abstract}
The urban heat island, a lesser known local phenomenon than global climate change, which is heating up most cities twice as fast as their surrounding countryside or the planet as a whole. Taken together, many cities suffer extreme heat, which threatens health and livability. Heat waves are growing more frequent, more intense and longer, with lethal impact. This essay presents strategies to combat extreme heat, including reducing waste heat from tailpipes and chimneys, lighter colored pavements and rooftops, better ventilated street canyons and more trees. The strategies to address heat islands are more like a Trojan Horse than the long frontal assault needed in the larger war to mitigate and adapt to climate change. In a world where urban living affords lower carbon footprints per capita, urban heat needs to be diminished so that people continue to migrate to cities, and that urban dwellers do not decamp to the countryside. Greater detail on the antidotes to this worldwide problem can be found in the author's new book THE URBAN FIX, Resilient Cities in the War Against Climate Change, Heat Islands and Overpopulation.
\end{abstract}

Keywords Urban Heat Island, Heat Wave, Waste Heat, Street Canyons, Environmental Paradox of Cities, Carbon Footprint, Climate Change

\section{Urban Heat}

Heat thrives in cities. They are giant thermal flywheels. All the dark roofs, walls, roads and other surfaces absorb and retain heat during the day, releasing it in the cities on a 24/7 basis. All the dark roofs, walls, roads and other surfaces absorb and retain heat during the day. Waste heat, emitted from air conditioners and vehicles, concentrates in cities too. At night, the temperature differences widen. Cities may be as much as $12^{\circ} \mathrm{C}$ hotter than surrounding areas in the evening hours, because their buildings release heat absorbed during the day. UHI is the term that describes this concentration of higher air and surface temperatures in cities compared to their surrounding territory. UHIs are brought on by dark surfaces overheated by the sun and "waste heat," i.e., hot emissions from tailpipes, chimneys and air conditioners (AC). The UHI typically extends beyond the urbanized area, tapering off with distance. Because it occurs on top of warming from $\mathrm{CC}$, these islands of heat and related heat waves are making many cities less and less hospitable for human occupation, even dangerous to the health of its residents. The U.S. Global Change Research Program stated with high confidence in 2017 that UHIs will strengthen in the future as the structure and spatial extent as well as population density of urban areas change and grow. ${ }^{\mathrm{i}}$

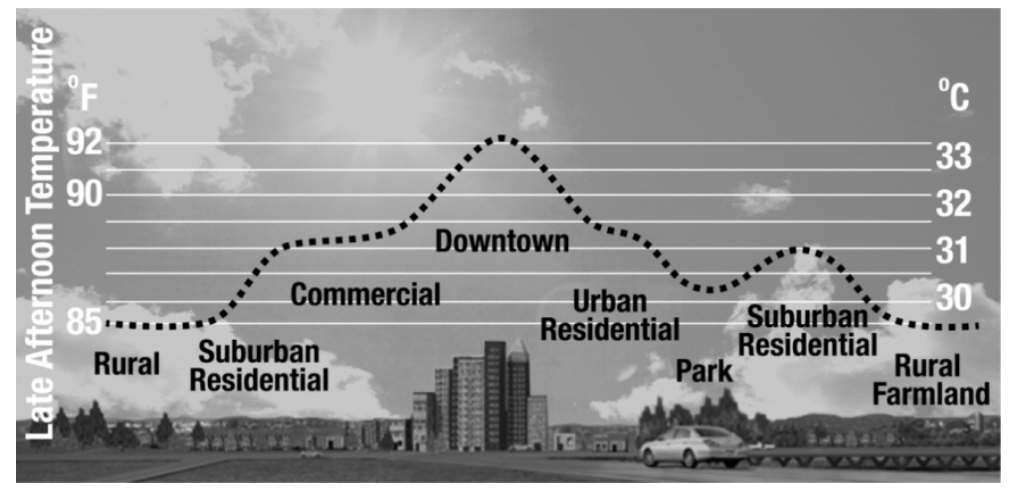

Figure 1. Cities are heating up twice as fast as their surrounding countryside and as the planet as a whole. The rural to urban temperature gradient is typically from $2^{0} \mathrm{~F}$ up to $18^{0} \mathrm{~F}\left(2^{0}\right.$ to $\left.10^{\circ} \mathrm{C}\right)$, depending on the size, density, color and impermeability of the city. The difference can double in extreme heat waves. (Heat Island Group, Lawrence Berkeley National Laboratory) 
The UHI is easily conflated and confused with CC. Although both are anthropogenic, they have different physical causes in terms of their physics and chemistry. CC is a far greater threat to humanity. Its science has been understood much longer, since it was first described in 1854 , and is more widely followed by the scientific community. As noted earlier, CC results from changes in the composition of the earth's atmosphere, specifically more GHGs, directly or indirectly released by human activity. Currently some $25 \%$ of carbon molecules in the atmosphere are man-made $\mathrm{CO}_{2}$, added since the Industrial Revolution and spiking since globalization started in the 1980s. In 2013 its accumulation reached 400 parts per million (ppm), which is higher than any time in the last 3 5 million years. ${ }^{\text {ii }}$ Short-wave solar radiation easily passes through our atmosphere and hits the earth (unless it is intercepted by and reflected back by clouds) and is absorbed by the earth's surface. Increased GHGs, most notably $\mathrm{CO}_{2}$, in the earth's upper atmosphere, trap more of the solar heat that bounces back - re-radiates at a longer wavelength to be more precise- from the earth's surface. Like the glass in a garden greenhouse, GHGs are transparent to the incoming shorter wave radiation from the sun, but they absorb the longer wave radiation that is radiated back from the land or water. Hence the name "greenhouse effect." Because the earth cannot bounce as much heat back to space through an atmosphere ever-thicker with GHGs, its surface and air temperatures are slowly getting warmer.

Although compounded by the global phenomenon CC, the UHI is a local phenomenon. It has not measurably raised the earth's temperature, whereas CC is raising the average global temperature and disrupting the climate. Climatologists tend to see local weather as "contamination" of global CC studies. The increase in local temperatures, as previously noted, is more from a local increase in sensible heat. Sensible heat can be felt, as opposed to latent heat, which is held in a material, and can't be felt until it is released in phase changes, from vapor to liquid to solid. As also noted, this palpable heat has two basic causes: the first is heat from dark surfaces, such as dark-colored rooftops, streets and parking lots that have absorbed solar radiation. This heat results in more radiation, conduction and convection of heat, like dark sand on a sunny beach, which burns by conduction, warms by radiation, and heats the air by convection. The second is waste heat from internal and external combustion of fossil fuels or discharged as hot air from air conditioners. It in turn induces more air conditioning, which spews more waste heat and consumes more electricity from power plants, whose emissions in turn add to CC. It's a self-reinforcing negative cycle, a non-virtuous spiral that is overtaking many urban climates.

These anthropogenic heat sources boost urban temperatures higher than the surrounding countryside, which has fewer tailpipes, chimneys, dark surfaces and air conditioners per acre, not to mention the lack of narrow urban street canyons that further entrap heat. "Because of the 'urban heat island' effect, cities of a million or more people can be $1.8-5.4^{\circ} \mathrm{F} \quad\left(1-3^{\circ} \mathrm{C}\right)$ warmer on average-and as much as $22^{\circ} \mathrm{F}\left(12^{\circ} \mathrm{C}\right)$ warmer in the evening - than the surrounding area, according to the U.S. Environmental Protection Agency." iii The relative contribution of waste heat and of heat from dark surfaces and street canyons varies from city to city. UHIs are strongest during calm and sunny weather, when extreme heat is more likely to cause discomfort, sickness and, in the case of severe heat waves, death.

\section{Why Are UHIs Timely?}

Fortuitously, the local ways to mitigate and adapt to UHIs are essentially identical to ways to address global CC. And because they're a shorter, perhaps a 10-year challenge, rather than a 100-year challenge, UHIs can more immediately and effectively rally individuals and societies to change their behavior. As highlighted earlier, they are local, more in-your-face, and more manageable, with actionable steps that give quicker feedback. Because UHIs beget quick, concrete attention, addressing them tends to feel more proactive and satisfying than trying to deal with longer term, more uncertain climatic trends and impacts, such as very gradually rising sea levels or slowly declining agricultural yields. Since uncomfortably and sometimes dangerously hotter temperatures tend to be inescapable in the city, urban cooling initiatives can galvanize public action from a broad socio-economic cross-section of the city, among poor constituencies that are pre-occupied with basic survival and among wealthy elites who can't fully escape heat in their air-conditioned lifestyles. Because the UHI threatens individual health and life expectancy, it is a personal stimulant to act. And as an urban phenomenon, it aligns well with municipal governance, which has been and promises to continue to be the most proactive level of government in combatting CC. ${ }^{\text {iv }}$

To reinforce this point: three out of the four strategies to cool the local thermal commons simultaneously address the global thermal commons. Because the causes are more tangible and obvious than with CC, there is the added benefit of defusing partisan or sectarian skepticism and denialism in politically and religiously conservative communities about both the human-centric causes and the urgency of global CC. Everyone can feel in real time the heat radiating off hot, dark surfaces, and coming out of tailpipes and air conditioners. City-goers and urban dwellers of all persuasions and cohorts can be overheated in narrow streets edged with tall buildings that trap hot air and reduce air natural flow. They appreciate the shade from trees and welcome cooling breezes. There's no esoteric science about invisible gases trapping infrared heat in the upper atmosphere and reradiating it back to earth. And there's less concern about apocalyptic tipping points with 
UHIs. There's also little if any excuse for pushback from skeptical or weak-kneed politicians. It provides a way to fight CC without even using the term. In summary, UHIs, often highlighted by heat waves, are more immediate, understandable and less controversial. And the manifestations and consequences of extreme heat in cities are getting demonstrably worse faster than CC.

This question brings us to one of the book's bedrock issues and new contentions: why it is beneficial and opportune in climate and other terms for more people to live in cities. Compared to their suburban and rural counterparts, urban residents in developed countries tend to have smaller ecological footprints. (Ecological footprint, or "eco-footprint," is the metric that measures the equivalent land area needed to provide the resources consumed and to absorb the wastes.) Typically, the eco-footprint closely aligns with the energy and carbon footprints, whether the scale is the home, community, region, nation or world. Urbanites walk, bike and use transit more than auto-dependent suburban and rural residents, as New Urbanists Scott Bernstein, Hank Dittmar and Jackie Grimshaw first pointed out with striking maps of Chicago in the early 2000s. Additionally, the more compact, party-wall/multi-floor housing in cities takes less energy to mechanically heat and cool, as do the larger buildings in which they usually work. Their smaller homes, very often in multi-family buildings, tend to encourage less acquisition of material possessions, compared to suburban McMansions, with their larger rooms, extra bedrooms, attics, garages and lawns. A Canadian study of Ontario housing reported that "nearly two-thirds of the province's households live in homes that are bigger than what they need, with more than 400,000 homes that count three or more empty bedrooms." (On the other hand, it is no doubt true that wealthy urbanites often consume more energy on air travel, fashion and luxury items, as well as larger apartment and condominium units.)

All of these benefits constitute the surprising, important and welcome environmental paradox of cities, a central theme of the book. It can be summarized as urban residents on average have smaller footprints than their suburban and rural counterparts. The suburbs may look green with their verdant leafiness and landscaped lawns, but in fact they are environmentally gray.

Real action requires that long-term threats are made threateningly real, and ways to act are present and clear. Many, many reasons to act are precipitated by the public disruptions of thermal and environmental events and crises - from urban congestion, overpopulation, air and water pollution to health problems, social unrest and infrastructure failure, not to mention the more direct CC phenomena of sea level rise, extreme weather, storm water flooding, drought, famine, climate refugees, etc. The particular cocktail of concerns varies from climate to climate, culture to culture, and economy to economy. For many urbanized places, especially those in hot climates, rising urban temperatures are already stirring up trouble. Indeed, the loss of air-conditioning in a Middle-Eastern city during a 2015 summer heat wave is reputed to have triggered civil unrest that was more intense than the civil war raging in the area, made all the more violent because state officials were spared the hardship.

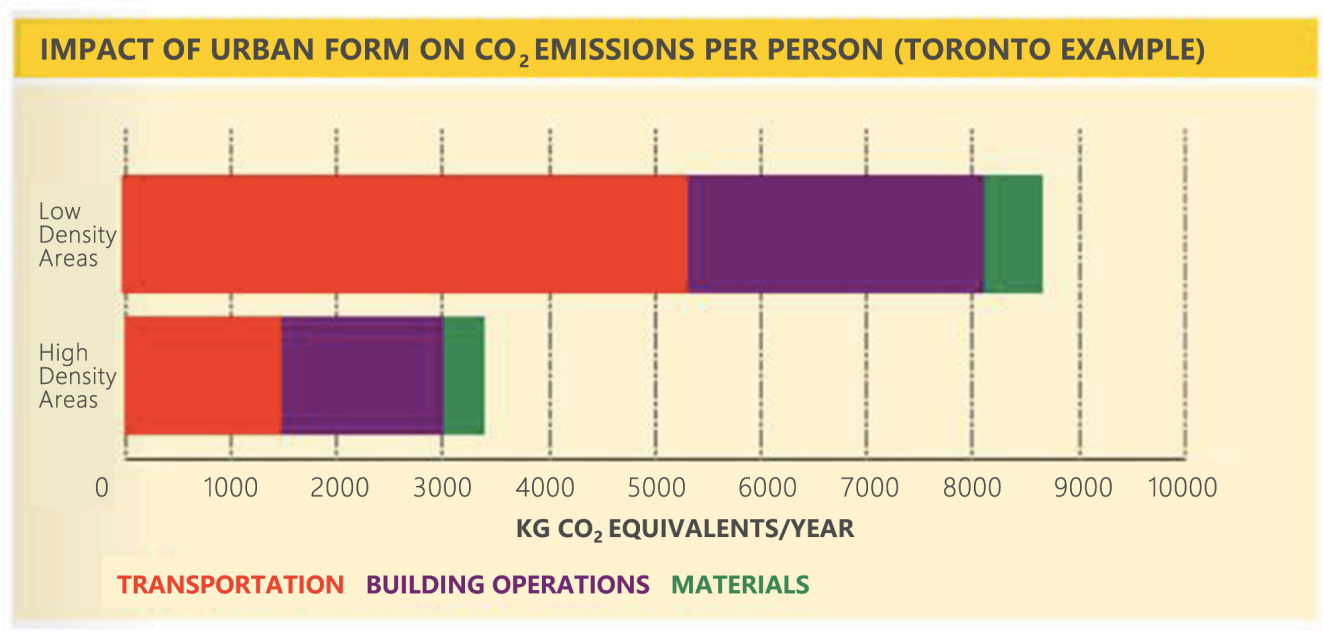

Source Journal of Urban planning and depelopment (2006)

Figure 2. High density areas in the U.S. have considerably smaller carbon footprints per capita than low density areas, with transportation and building operations (heating, cooling, lighting, equipment) constituting most of the difference. America epitomizes this environmental paradox of cities, but it also obtains in most cities in developed countries that have auto-dependent suburbs with freestanding houses. The paradox is found more and more in the megacities of the developing world, as they decant more residents to their mushrooming periphery where their footprints expand. (Heather L. MacLean, University of Toronto) 
Worldwide, heat waves kill more people than any other type of natural disaster, including hurricanes, tornadoes, earthquakes and floods. "vi "Heat kills ten times more people in the U.S. than tornadoes or other extreme weather events." "vii It should be mentioned that the young, the sick, the elderly and those without social networks are typically more affected by the dangers of heat waves, whereas other more violent natural disasters injure and kill more indiscriminately. Poverty makes extreme heat harder to handle. "Excess mortality rates during extreme heat events are likely to be higher in the hottest neighborhoods; vulnerability and susceptibility in these areas are enhanced by poor socio-economic status, as expressed through poor housing quality, reduced air conditioning prevalence, and low household income levels.”viii If the elderly poor can’t afford an air conditioners, much less to run them 24/7 during a heatwave, they are in danger of getting sick or dying. Although the poverty-stricken usually suffer the most in heat waves, there are examples of poor neighborhoods where healthy social infrastructure has proven to make a dramatic difference in how quickly and effectively these neighborhoods respond and recover. This difference was famously and positively shown in adjoining poor communities in a devastating Chicago heat wave, where healthy social integration fostered highly effective communication that helped one neighborhood react and rebound with astonishing higher speed. ${ }^{\text {ix }}$

Outdoor urban heat is often so intense in hot, humid places like south Asia, that it can be physically sickening in the short term, including leading to heat stroke. And it can lower productivity in outdoor jobs and social interaction in the long term. UHIs tend to discourage outdoor activities, even in the evening, which is a traditional time for outdoor socializing and cultural events. But slum residents in cities like Dhaka - almost half Bangladesh's population - are reportedly too preoccupied and stricken with poverty to be aware of, much less understand and be concerned about CC. They are aware of extreme heat and regularly suffer its toll on their health, productivity and outdoor socializing. "One study in Bangladesh showed that extreme heat is more likely to drive migration than flooding is...Future sea level rise gets far more attention and study than increases in extreme heat, which may actually have a larger impact a lot sooner." ${ }^{\mathrm{x}}$ The people of South Asia make up nearly a fourth of humanity, and so what happens to them stands to have inevitable global repercussions on everything from migration to conflict.

Although much of the new urban commercial space is air conditioned in developing countries, when there is power loss or load-shedding, these buildings become suffocatingly hot because their large floorplates, party walls and lack of operable windows make it difficult to naturally ventilate. The fairly frequent blackouts result in discomfort, reduced productivity, and physical and mental stress. In passing, it is worth noting that the advent and worldwide spread of air conditioning and florescent lighting, and now even cooler LED bulbs, have enabled commercial buildings with much bigger floor plates than traditional buildings, which needed daylight and operable windows relatively close to occupants. Today's fatter buildings, which would be too hot if lit with incandescent bulbs, are difficult to naturally ventilate, because much of the floor space is too far from windows, which often aren't operable anyway in the ubiquitous sealed glass boxes of modern architecture. It could be said that the cooler florescent and LED lights have enlarged the horizontal dimension of architecture much as the elevator famously heightened its vertical dimension.

UHIs can extend well beyond the city, especially in the direction of the prevailing wind. When air flows over the hotter urban surfaces, a layer develops that "deepens with distance from the upwind edge. This envelope may be 1-2 kilometers thick by mid-afternoon and is distinguishable as a warm and turbulent atmosphere that is enriched with contaminants, including GHGs.” ${ }^{x i}$ This extensive layer means that higher temperatures and heat waves can impact wealthy areas of the metropolis, even though these neighborhoods are often more open to breezes and have more shade from foliage. UHIs can be dodged to a limited extent by the wealthy citizenry, but the combination of UHIs and CC is ultimately too pervasive for them to escape if they want to live within a metropolitan area, especially in one of its centers. In the short run, the rich can move to cooler climes and have the space and wherewithal to stock supplies, but systemic breakdowns and geopolitical strife caused by a disruptive climate are inescapable. Among other hindrances, it will be the little things - such routine matters as getting spare parts for luxury paraphernalia - that will become more and more difficult.

The cooler countries of northern Europe have carbon footprints per capita significantly lower than other developed countries, because they have found effective ways other than polluted air and/or extreme heat to rally their citizens, institutions and corporations. Public policy, incentives and education have been effective. Whatever the prevailing motivator or wherever, policies and actions must be democratically prioritized and coordinated, with bottom-up input from citizens, as well as advice from experts. Prioritizing is critically important, because there is neither enough money to solve civilization's problems all at once, nor enough time to solve them one at a time. For instance, given the triple threat of CC, overpopulation and budget constraints, the economic and political reality is that infrastructure projects now have to serve multiple purposes. Synergies, efficiencies and co-benefits are essential, even in the wealthiest countries, which can sometimes be the sloppiest and most wasteful on both a total and per capita basis. Co-benefits of reducing UHIs and CC include less air pollution and smog, more jobs, healthier and more livable cities, longer lifespans of building materials, cleaner and cooler water for drinking and industrial uses, and less electricity consumption for air conditioning. Electricity for 
AC in cities increases 2 - $4 \%$ for each $1.8^{0} \mathrm{~F}$ or $1^{0} \mathrm{C}$ increase in temperature, and it is fast becoming a major share of worldwide energy consumption. ${ }^{\text {xii }}$ Whatever the motivator or the reason to act, climatologists tell us we have no time to waste.

This brings us to related paradoxes of the city. The third one is the thermal paradox of cities. It is simply the flip side or cognate of the environmental paradox of cities: Although living in the city can increase the local temperature, it can simultaneously help cool the planet's temperature. In other words, as the city gets hotter, urban dwellers may nonetheless have a positive effect on global CC, due to smaller average footprints than their suburban and rural counterparts. Their thermal suffering is not in vain. Yet another way of stating it is that even though cities are getting hotter faster than the local countryside by concentrating heat in urban islands, cities exercise an overall cooling impact on the global climate. Unlike the first two paradoxes, which are causative, this paradox is only correlative, i.e., hotter cities don't actually combat CC, but they tend to accompany it. However, if the four strategies to fight UHIs presented in upcoming chapters are followed, the tendency toward hotter cities can be diminished, even eliminated. And the consequences of the first three of these four urban paradoxes cannot be overstated or underestimated, as they hold the key to the very positive role that cities can play in the long, slow war against CC.

Nevertheless, UHIs can give cities a bad name for being hotter than suburbia and the countryside at precisely the time when it's important to encourage people to move to and remain in urban places. In the developed countries, UHIs could jeopardize the attendant climatic benefits. Suburban and rural developers can advertise cooler environments. Indeed, if the thermal differential between core and periphery is allowed to become severe enough, it could even trigger migration out of central cities. This reversal would tend to aggravate CC for two reasons. First, the carbon footprints per capita would increase in developed countries and, second, family size and the total number of people would increase in developing countries, since suburban and rural families tend to be larger. These possible outcomes underscore why UHIs need to be aggressively addressed immediately, with as little fanfare as possible about hotter city temperatures.

\section{Related Urban Challenges and Opportunities}

Higher air temperatures have other deleterious impacts. Stifling hot cities are more prone to disease, civil unrest and ultimately violence. Several quantitative studies have been compiled on the general relationship between heat and violence. A statistical analysis in 2000 showed that "there were 4.6 additional murder/assault crimes per
100,000 people in the United States for an increase in temperature of $1^{0} \mathrm{~F}$. Using a population of 270 million, a temperature bump of $2^{0} \mathrm{~F}$ led the researchers to predict that there will be 24,000 additional murders or assaults per year. An $8^{0} \mathrm{~F}$ rise would produce about 100,000 additional crimes." "xiii And this doesn't assume any rise in collective unrest and mob violence, which would be likely to arise in many cities in already hot climates that get hotter. Indeed, another study found that climate's influence on modern conflict is "substantial and highly significant. A temperature bump of about 34\% from the mean was associated with a $4 \%$ increase in inter-personal violence and a $14 \%$ increase in intergroup violence."xiv

Writing about Mexico City, Michael Kimmelman quotes a Columbia University report that found "where rainfall declines, 'the risk of a low-level conflict escalating to a full-scale civil war approximately doubles the following year.' And nowhere does this apply more obviously than in cities." ${ }^{\mathrm{xv}}$ On the relationship between temperature and large-scale violence, researchers say that "for every half-degree of warming, societies will see between a 10 and $20 \%$ increase in the likelihood of armed conflict. In climate science, nothing is simple, but the arithmetic is harrowing: A planet five degrees warmer would have at least half again as many wars as we do today. Overall, social conflict could more than double this century." "xvi The question hanging over these findings is whether human societies can both reduce extreme heat and learn to better cope with it.

Cities, with their many, many moving parts and complex systems, can also lack resiliency in times of disaster and panic, including heat waves. Nonetheless, if cities in developed countries are to play the positive, synergistic and catalytic role that they can naturally assume in the ongoing fight against CC, there is no choice but to retrofit them to be cool enough for human health, comfort, productivity and civility. Similarly, new and expanding cities in developing countries must be planned and built to prevent, mitigate and adapt to, the UHIs from the outset. The issue has to be framed in an honest but positive light and in affirmative ways to motivate the public. It should be presented as an opportunity to protect and increase the pleasure and comfort of living in cities, both in developing and developed countries.

No antidote to UHIs is more universally beloved than trees. Having slowly evolved on the forest edge of the African savannah under sunlight dappled by foliage, we humans have come to like trees and see them as beautiful. They are cooked into our genes. Planting these multi-taskers in cities is a win in so many ways to mitigate and adapt to both CC and UHIs that a whole chapter is devoted to urban trees. It is an appealing, low-tech, time-tested practice that sequesters $\mathrm{CO}_{2}$ and reduces air pollution, soil erosion and storm water runoff, not to mention providing oxygen, habitat for small animals, shade in the summer and more. And urban street trees are not as burdensome to maintain as the more numerous and more 
ornamental trees of suburbia. A clever if corny slogan of mine is "Plant a TREE on your sTREEt." The benefits of trees are bumper-sticker simple, which is important in framing their numerous benefits. They can be sold as improving the quality of life by increasing safety and health, while reducing congestion and pollution. Their planting and maintenance can be implemented as private, neighborhood or governmental initiatives. Indeed, tree-planting programs can be civic, even patriotic campaigns, such as the 19th Century planting of American Elms that made scruffy towns beautiful in the Midwest and Northeast. Affectionately described as "cathedrals of shade," these iconic trees came to symbolize leafy American streets and college campuses. Installing green roofs can provide similar aesthetic and ecological benefits, but plants growing on terra firma have inherent advantages, especially in terms of installation, replacement and maintenance costs.

Reducing waste heat by converting our urban transportation system from cars to transit, shared vehicles, bicycles and walking will require a stronger framing effort. It's a bigger and costlier sea change than tree planting. Organizations like the Congress for the New Urbanism (CNU) and Smart Growth America have successfully promoted Transit-Oriented-Development, a.k.a. TOD, a term now familiar around the world. Countless conferences have been convened, and a torrent of books and articles have been published about the benefits of less automobile-dependency. They are part of an effort to replace suburban sprawl with settlement patterns that are more mixed-use, mixed-income, connected, accessible, compact and denser - all of which promote walking, biking and transit.

Because urban cooling emphasizes adaptation over mitigation, its more immediate and concrete initiatives provide a proactive sense of progress against the vagaries and uncertainties of unfurling CC. And if cities fail to attract more residents, and/or to keep their current residents from migrating to their relatively cooler suburbs and countryside, their larger carbon footprints will eventually make both cities and suburbs hotter by exacerbating CC. It is about managing public perception, as well as mobilizing to respond to a costly and accelerating physical imperative. Cooling the local urban thermal commons, like addressing $\mathrm{CC}$, sits on the right side of multiple equations. And there can be few if any regrets about mitigating UHIs, as the benefits of less extreme heat - from comfort to health to social life - are good for the world in any case. In short, UHIs are a great reason and a great motivator to address both local extreme heat and global CC.

Are UHIs a Trojan horse in the battle against extreme heat?

“...large cities in the U.S. are warming at more than twice the rate of the planet as a whole. ...global estimates of climate change are likely to underestimate rates of warming in the very places where most of the global population now resides: cities.”[17]

Brian Stone, The City and the Coming Climate, 2012

Professor Sone's impoetant book focuses on U.S. cities, but it's safe to assume other cities are heating up as fast. To reach his conclusion, he left out the 14 of the 50 cities in his statistical sample. If the coastal cities, which are cooled by sea breezes, are included, the full sample was found to be warming at 1.5 times the average rate of the planet. The temperature increases in rural areas and on the planet as a whole are typically happening at the same rate. The Arctic region, which lacks cities, is also heating up at twice the average global rate, but for different reasons. ${ }^{\text {xvii }}$ The New York State Energy Research and Development Authority reported more extreme results for New York City: local temperatures recently rose by $2.4 \%$ over a span of 40 years, which is more than two times the average for global temperatures.

Ironically, UHIs are usually more pronounced in winter than summer - or in the "cool" and "hot" seasons, as they are called in some countries - when they are less noticeable and less problematic. The extra heat in winter brings benefits - fewer weather-related deaths, lower heating costs, more outdoor comfort, fewer travel hazards, such as less ice on walking and driving surfaces. In fact, far more people annually die in the U.S. from weather-related vehicle accidents (annual average of 6,000) than from tornado, hurricane, lightning, flood or extreme heat events (average annual total of 375). ${ }^{\text {xviii }}$ And moderating cold is generally more favorable for plant and animal life. Regardless of how welcome the extra warmth and resulting drop in cold-related deaths may be in winter, UHIs have become a pressing problem in summer. In the cities that are currently hot, which are home to the majority of the world's urban dwellers, they are rapidly making them more dangerous than the surrounding countryside, especially when there are heat waves. A useful term for the combination of UHIs and heat waves is "extreme heat." It is here that we start the tale of how cities combat CC.

The urban heat island effect (UHIE) is the full technical term, coined in the 1940s to describe the higher air and surface temperatures in cities compared to their hinterland. These "reverse oases" have been observed for two centuries, with the first documentation done in a seminal if amateur study of London's climate in 1818, followed by studies in Paris later that century. Systematic study of heat islands in the U.S. commenced in the mid- $20^{\text {th }}$ Century, before CC was the high-priority concern that it is now. "Until the 1980s, this effect was considered to have relatively little practical significance. In fact, given that most studies were done in cities with cold winter climates, a warmer temperature was seen as a potential benefit, because it reduced the need for heating." xix Since then, concern about UHIs has emerged and escalated, along with ways to minimize them.

Whether writ large or small, in warm or cold areas, UHIs 
happen in almost all urban areas. ${ }^{\mathrm{xx}}$ Despite their physical and climatological variety, research on UHIs has suffered from a relatively vague and simple distinction between urban and rural areas. In 2012, two Canadian geographers developed a more precise classification system, with 17 Local Climate Zones. The ten "built types" range from Compact and Open High-rise, Mid-rise and Low-rise to Lightweight (wood single-family houses) and Open Low-rise (e.g., office park), plus Heavy Industry. The seven "land cover types" include Dense and Scattered Trees, Bush/Scrub, Low Plants (grassland, agricultural farmland and pasture), Bare Rock or Paved, Sand, and Water. The many combinations of built and land cover types, not to mention ephemeral conditions like snow, foliage and wetness. The system is suitable for UHI researchers, as well as urban planners, landscape ecologists, and CC investigators, but too detailed for this book.

The five causes of UHIs:

1. Greater absorption, caused by the low urban albedo (solar reflectivity) of dark surfaces and the entrapping geometries of buildings and the spaces between them

2. Greater retention, due to less openness to the sky and less natural ventilating in street canyons

3. Greater absorption and delayed release of solar heat by buildings and paved surfaces

4. Greater proportion of absorbed solar radiation converted to sensible heat, which we can feel, rather than latent heat, which we can't feel. (Pavements and roofs do not absorb as much heat as plants and moist soils, which go through a phase change that takes up additional heat without raising its temperature.)

5. Greater release of heat from combustion of fuels for transportation, industrial processes, and space heating and cooling, summarized as "waste heat" in this book

The UHI is easily conflated and often confused with global CC, as noted earlier. One way to illustrate the difference is to examine the thermal behavior of a common automobile. We're all familiar with heat that is produced by combustion in the engine, much of which is released from the tailpipe in the form of hot gases. These hot fumes waste heat - elevate the nearby air temperature. Then there's the solar radiation absorbed by the body of the car, which heats the steel shell to a temperature exceeding the ambient air temperature. The darker the paint color, the hotter the surface. This hotter surface warms nearby air by convection currents and nearby objects and people by radiant heat - or by conduction if they happen to touch or lean against the car. These three modes of heat transfer, plus waste heat are responsible for UHIs.

Then there's the overheating of the car's interior, which is a function of the exterior and interior colors and the window configuration. A recent study found that after parking in the sun for an hour, a silver car had a cabin air temperature about $9-11^{\circ} \mathrm{F}$ lower than an otherwise identical black car. ${ }^{\mathrm{xxi}}$ The amount of glass and the color of the upholstery play a much bigger role - one that is uncannily equivalent to global warming. The temperature in a closed, sunlit car can increase $20^{\circ} \mathrm{F}$ in only 10 minutes, and 33 degrees in 20 minutes. ${ }^{x x i i}$ Seats soak up the solar radiation that comes through the windows, which are transparent to short wave radiation that makes up most of the sun's energy (only half of which is visible to the human eye). The seats get hot, especially dark-colored ones, and re-radiate the heat, but at a longer wavelength (invisible infra-red radiation as opposed to visible light or shortwave radiation). The longer radiation waves that hit the glass are absorbed. Half is re-radiated outwards and half back into the car's interior, trapping half the solar heat inside the car. This same physics happens with the greenhouse effect at the planetary scale; the earth's atmosphere acts in the same way as the car's windows. But it is GHGs, rather than window glass of the car (or in a garden "greenhouse," GHG's namesake) that trap the infra-red heat radiating upward from the earth's surface. Like anyone with dark automobile upholstery knows, it's a potent effect.

In short, the increase in GHGs, most significantly $\mathrm{CO}_{2}$, in the earth's upper atmosphere causes it to trap more of the solar heat re-radiating from the earth's surface. To refine this important point, GHGs are selective permeable filters that are transparent to the incoming shorter wave radiation from the sun but absorb out-going longer wave radiation. The warmer atmosphere in turn triggers changes in land, air and ocean temperatures, with ensuing impacts on everything from biodiversity and ecosystems to human civilization. Hence the term "global warming" has given way to "climate change" to reflect the fact that not all parts of the planet are getting warmer, and that some areas are getting cooler. 


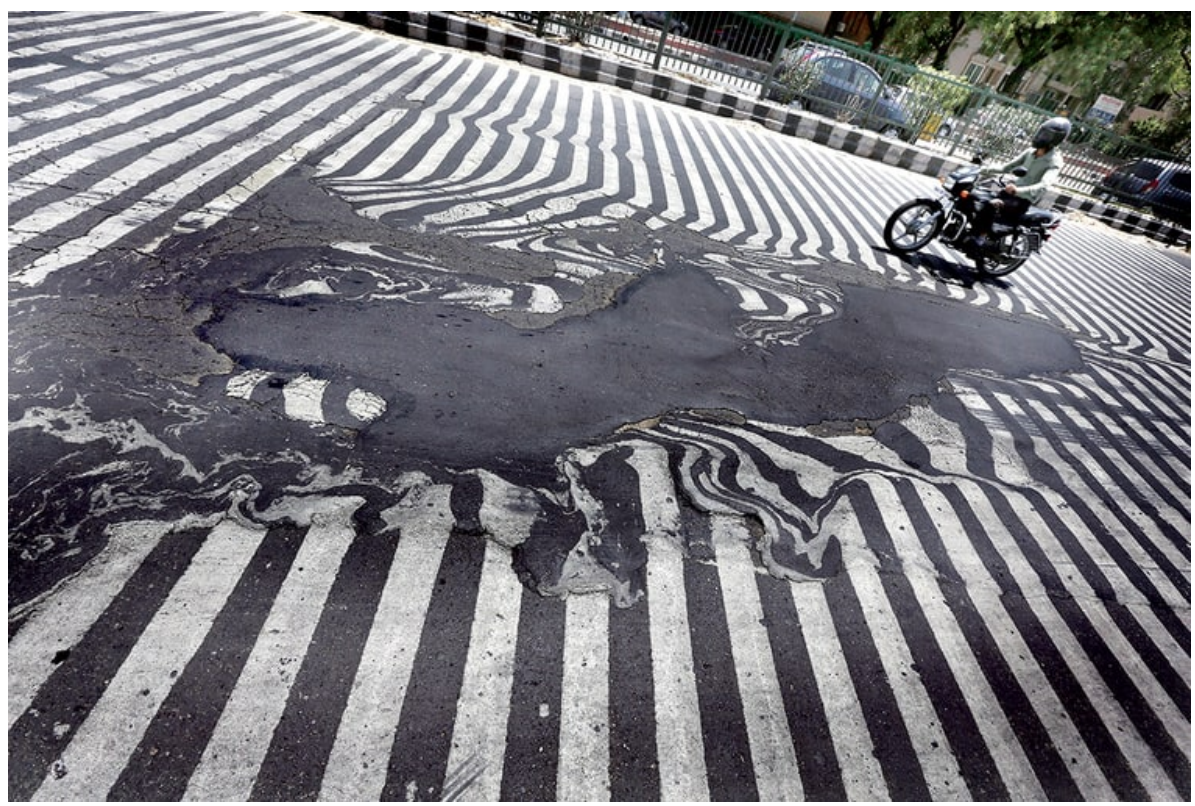

Figure 3. Air and especially surface temperatures are higher in the central city than surrounding suburban and rural areas. This melted asphalt is in an Indian city, where pedestrians crossing the street have been known to lose their shoes to the melted, sticky road surface. (Photo by Harish Tyagi/Epa/REX/Shutterstock (7978897g))

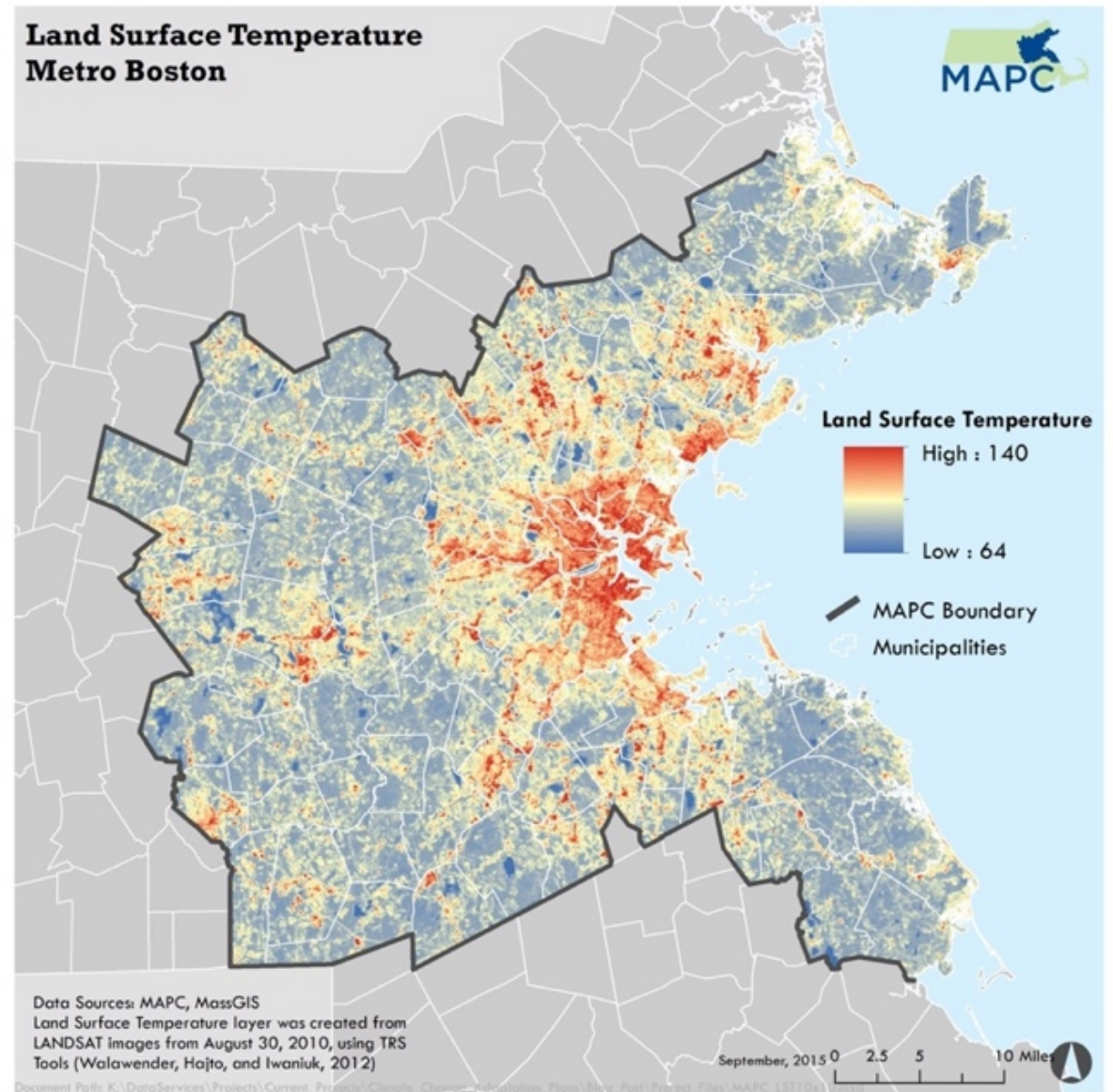

Figure 4. The map of land surface temperatures depicts metropolitan Boston in late August, when the average surface temperature during the day is as much as $76^{\circ} \mathrm{F}$ higher than the average air temperature. "Temperatures of dark, dry surfaces in direct sunlight can reach up to $190^{\circ} \mathrm{F}\left(88^{\circ} \mathrm{C}\right)$, while vegetated surfaces with moist soil under the same conditions might reach only $70^{0} \mathrm{~F}\left(18^{\circ} \mathrm{C}\right)$. Anthropogenic heat, slower wind speeds and air pollution in urban areas contribute to the formation of UHIs.[21] (MAPC, MassGIS) 


\section{Human Health}

Health hazards bring us to the first of many physiological impacts of extreme heat. Humans are endotherms, which means that various mechanisms keep our core body temperature within a normal range of 97.7 $99.5^{0} \mathrm{~F} \quad\left(36.5-37.5^{\circ} \mathrm{C}\right)$. This thermoregulation is controlled by the hypothalamus, a part of the brain that acts like a biological thermostat connected to temperature-sensing nerve cells. As temperature increases - depending on age, time of day, and level of activity and emotions - the body attempts to cool down. "One way to do that is by secreting water with dissolved ions - sweat. Water absorbs heat so as sweats evaporates it liberates heat by evaporation, that's why sweat cools people down...The problem with heatwaves is that excessive heat can put humans under a lot of physiological stress. Because sweating is the most effective mechanism, during hot weather the people who are most vulnerable are the ones whose sweating mechanism is, for various possible reasons, subpar - the elderly, the chronically ill and children, as well as pets.”xxiii As Gregory Wellenius, an epidemiologist at Brown University, says "There's a point where the human body can't cool itself, which means you are either in an air-conditioned space or you're having serious health problems..."xxiv

"Humans, like all mammals, are heat engines; surviving means having to continually cool off, like panting dogs. For that, the temperature needs to be low enough for the air to act as a kind of refrigerant, drawing heat off the skin so the engine can keep pumping...that would become impossible for large portions of the planet's equatorial band, and especially the tropics, where humidity adds to the problem; in the jungles of Costa Rica. For instance, where it routinely tops $90 \%$, simply moving around outside when it's over $105^{\circ} \mathrm{F}$ would be lethal. And the effect would be fast: Within a few hours, a human body would be cooked to death from both inside and out." ${ }^{\mathrm{xxv}}$ Human discomfort typically starts above $100^{\circ} \mathrm{F}$; life threatening conditions arise at $104^{\circ} \mathrm{F}$ and get more and more serious with temperatures above $106^{\circ}$, with brain damage and death normally occurring above $109^{\circ} \mathrm{F}$ and certain death at $111^{0}$ or higher. When the body temperature is in or near the normal range, comfort depends on several factors - the temperature of the air and surrounding surfaces, the humidity, and the air speed. The psychrometric chart combines these and other variables (dry and wet bulb temperatures, dew point, relative humidity, enthalpy, air density or pressure, but not air speed or temperatures surrounding surfaces) to provide a window of comfort. Ventilation, dehumidification or air conditioning by natural or mechanical means is highly desirable, even necessary for survival, when warmer or more humid conditions prevail.

Here's a list of possible health problems and medical maladies:
- Heat rash occurs when the sweat glands become blocked, trapping perspiration under the skin and causing a red, itchy rash. It is more common among babies and young children, and usually does not require medical attention.

- Heat cramps are muscle spasms that happen during heavy exercise in hot weather, with medical treatment rarely needed.

- Heat exhaustion is brought on when evaporative cooling from perspiring skin begins to fail. Profuse sweating and dehydration set in, often accompanied by dizziness, faintness, weakness or excessive fatigue, as well as weak pulse and low blood pressure. Rehydration is essential, and worsening symptoms require immediate medical treatment.

- Heat stroke, also called hyperthermia, happens when the body can no longer regulate its core temperature, causing lethargy, confusion, delirium, loss of consciousness and, in the worst case, seizures. It requires an immediate ambulance trip to the emergency room. Failure to act quickly can lead to unconsciousness, irreversible damage to the brain, or death. $^{\text {xxvi }}$

In addition to children, the elderly and the chronically ill, others at risk include the obese and those with existing medical conditions such as diabetes and heart disease, as well as the socially isolated, and the poor. These maladies are more frequent out-of-doors than indoors, especially if there is air conditioning. While thermally more comfortable and generally healthier, air conditioning does not come without its unintended health consequences. Their filters remove particulate pollutants from outside, but it's not clear if they decrease indoor pollutants overall. "For reasons that are not well understood, air conditioning is associated with increases in acute health symptoms often called sick building syndrome (SBS) symptoms, and also with asthma symptoms. SBS symptoms include irritation of eye, nose, and throat, headache, and fatigue, and sometimes other effects." ${ }^{x x v i i}$ These afflictions will no doubt become more widespread as mechanical cooling spreads globally.

While it's obvious that heat-related ailments will increase with warmer climates, the link to infectious diseases is more complex, but just as credible and alarming. Warmer weather helps food-borne organisms like salmonella multiply more quickly, and warmer seas foster bacteria like vibrio that make shell fish such as oysters unsafe to eat. "Spikes in heat and humidity have less visible effects, too, changing the numbers and distribution of the insect intermediaries that carry diseases to people. When former Vice President Al Gore spoke (in 2017) at a meeting on climate and health, he chose to start his talk not with a starving polar bear or a glacier falling into the sea, but with images of mosquitoes and ticks. 'Climate change is tilting the balance, disrupting natural ecosystems and giving more of an advantage to microbes,' Gore said, 
standing in front of a giant image of...the mosquito species that transmits yellow fever and dengue, and now the Zika virus as well. 'Changing climate conditions change the areas in which these diseases can take root and become endemic.", "xxviii

A new scientific specialty called disease ecology has arisen to study the interaction of climate and disease carriers, with serious implications for public health. Diseases carried by insects are affected by the impacts of CC, especially flooding and more frequent and extreme precipitation. As Gore points out, controlling the notorious mosquito becomes all the more important, because various strains of this pesky arthropod spread can also spread West Nile Fever, not to mention the age-old scourge of malaria. Most of these are tropical diseases, but their geographic range will tend to expand on a warmer, wetter planet. And drought and famine will aggravate their effects by weakening human resistance, especially in poor rural and urban areas.

Environmental problems have been likened to human disease. University of Michigan Professor Scott Campbell, offers a telling analogy: environmental problems in the 1970s and 80s were thought to be akin to an acute illness or infectious disease that can be cured outright, but we have now come to see them more like chronic, degenerative diseases that are more systemic and not easily cured. Adaptation to CC might even be compared to long and careful palliative care for cancer, rather than remission. "We will likely not know, in the long run of history, whether human life is intrinsically unsustainable or whether mass urban society can live 'in harmony' with nature.' Planning's contribution is to carve out habitat niches that support life, in a volatile world, for a diverse array of populations with a minimum of misery and disparity. One can't 'cure' unsustainability. But one can treat it as a chronic, increasingly manageable disease: to incrementally transform a once fatal environmental deterioration into a tolerable condition." "xxix

There is another longer-term cost - a combination of a health and socio-economic issues. A growing body of research concludes that rising global temperatures not only increase the risk of heat stress and stroke, but that they effect children's health to the extent that it decreases their economic prospects as adults. A study by Stanford, the University of California, Berkeley, and the U.S. Department of the Treasury suggests that even short periods of extreme heat can carry long-term consequences for children and their financial future. "Fetuses and infants are 'especially sensitive to hot temperatures because their thermoregulatory and sympathetic nervous systems are not fully developed."” ${ }^{\mathrm{xxx}}$ Accordingly, heat waves during an individual's early childhood, including the period before birth, can affect his or her earnings three decades later. Exposure to just 23 days of temperatures above $90^{\circ} \mathrm{F}\left(32^{\circ} \mathrm{C}\right)$ before their first 21 months is estimated to cut a $\$ 50,000$ salary in later life by almost $5 \%$. And unchecked CC could reduce average global income by around $23 \%$ in 2100 , and as much as $75 \%$ in the poorest countries. ${ }^{x x x i}$ While these estimates may seem overly-precise and tentative, the overall trend is not.

\section{Heat Waves}

"Meeting fast-rising cooling demand with today's high global warming potential...is creating an environmental disaster - a veritable carbon time bomb."

Dan Hamza-Goodacre, Kigali Cooling Efficiency Program

Professor Edward Ng of the Chinese University of Hong Kong has been studying urban climate in his city since 2003. His research finds that waste heat from anthropogenic sources such as vehicles, factories and air conditioners contributes about $1^{\circ} \mathrm{C}$ to Hong Kong's heat island on average. There is minimal waste heat from vehicles: Hong Kong had the top 2017 world ranking for sustainable mobility, with inexpensive transit handling $90 \%$ of all daily trips, the highest rate in the world. ${ }^{\text {xxii }}$ The big UHI contributors are several: the low albedo of dark surfaces, the thermal absorption and retention of heat by large amounts of building mass, the notoriously dense urban configurations that trap heat and block ventilation of outdoor space, and the lack of vegetation. These factors add on average about $7^{0} \mathrm{~F}$ (raising the air from $28^{0}$ to $32^{\circ} \mathrm{C}$ ) in the summer daytime, which is the most critical time for human comfort and health, and about $11^{0} \mathrm{~F}$ degrees (from $24^{0}$ to $30^{\circ} \mathrm{C}$ ) in the summer night, making sleeping difficult without air conditioning. ${ }^{\text {xxiii }}$

If global emissions are allowed to continue at a high level, "additional nights of sleeplessness can be expected beyond what people normally experience...the poor, who are less likely to have air-conditioning or be able to run it, as well as the elderly, who have more difficulty regulating their body temperature, would be hit hard." xxxiv Professor $\mathrm{Ng}$ likes to point out that Hong Kong's thermal map closely aligns with the residents' economic status, with the poor living in the most uncomfortable areas and the affluent in verdant areas. In Indian cities, "templates of segregation are being remapped...and how class- and caste-based exclusions are being reimagined..." $\mathrm{xxxv}$ Indeed, the question of social equity within and between countries is underscored by UHIs. Of the $1.1 \mathrm{~B}$ people who face "cooling access risks," it's estimated that $630 \mathrm{M}$ are located in hot, poor slums with little or no cooling to protect them against extreme heat ${ }^{\text {xxxvi }}$ Within the U.S., people of color are up to $52 \%$ more likely to live in UHIs than white people, according to a UC-Berkeley report on 2000 census data ${ }^{\text {xxxvii }}$

UHIs are also harmful in hot arid climates. For instance, most of the American Southwest may be facing a deadly mega-drought worse than anything seen during the last 2,000 years. Scientists, including a group at NASA, think it's "a near certainty sometime not long after 2050 if 
carbon emissions continue along their current trajectory. Big cities in Texas, Florida, and Southern California are projected by 2050 to wither under $105^{\circ} \mathrm{F}$ days for about a third of the year." xxxviii In these and other arid climates with less vegetation, the UHI is strongest during dry periods, when the weather is calm and skies are clear. "These conditions accentuate the differences between urban and rural landscapes. Cities are distinguished from natural landscapes by...the extent of the urban land cover, the construction materials used, and the geometry of buildings and streets. All of these factors affect the exchanges of natural energy at ground level." "xxxix

Professor Stone has written that hot, humid American cities like Atlanta have experienced more climatic modification from its local UHI than from global CC. ${ }^{\mathrm{xl}} \mathrm{He}$ suggests that hotter temperatures amplified by the UHIE will soon make outdoor activities for more than a few hours a day too uncomfortable for most of its citizens. The authors of American Climate Prospectus "have predicted that residents of the Southeast are likely to experience between 56 and 123 days, or almost one-third of the year, when temperatures exceed $95^{\circ} \mathrm{F}$. The temperature of $95^{\circ} \mathrm{F}$ is not chosen arbitrarily...When the relative humidity is $100 \%$ this is the maximum temperature at which a normal, resting, well-ventilated individual can maintain a normal body temperature by the evaporation of sweat." ${ }^{\text {xli }}$ A 2018 global study "projects that in coming decades the effects of high humidity in many areas will dramatically increase. At times, they may surpass humans' ability to work or, in some cases, even survive...population exposure to wet bulb temperatures that exceed recent deadly heat waves may increase by a factor of five to ten, with 150-750 million person-days of exposure to wet bulb temperatures above those seen in today's most severe heat waves by 2070-2080...exposure to wet bulb temperatures above $35^{\circ} \mathrm{C}$ - the theoretical limit for human tolerance - could exceed a million person-days per year by 2080. In the coming decades heat stress may prove to be one of the most widely experienced and directly dangerous aspects of CC, posing a severe threat to human health, energy infrastructure, and outdoor activities ranging from agricultural production to military training." xlii

Indeed, heat extremes threaten large economic losses as temperature maximums limit outdoor activity and labor productivity. For outdoor laborers, such as those at construction sites, models of "work capacity losses" by 2050 for Southeast Asia during hot weather for moderate work in the shade at the height of the day are expected to be as high as $40-50 \%$, increasing to $60-70 \%$ in the sun. ${ }^{\text {xliii }}$ In the Southeast U.S., some roofing companies provide personal canopies for their roofers, as working in direct sun light is already too dangerous. These kinds of "personal micro-climates" may be needed more widely and more often, as temperature and humidity conspire to make outdoor work exceedingly difficult, if not impossible. Heat is making outdoor workers and poorer.
Heat waves are overtaking their bigger, more dangerous cousin CC as the more immediate problem. In most large American cities, there is an increasing need for "cooling centers" that are open to people whose homes are without air conditioners and dangerously hot. These air-conditioned sanctuaries are typically in institutional buildings open to the public, like municipal libraries and schools, where citizens can find relief, including extended stays if necessary. Evidence suggests that as annual deaths from heat waves increase, ${ }^{\text {xliv }}$ more of these centers will be needed to cope with hotter and longer episodes of extreme heat. Health officials report that getting people to cooling centers can be a challenge: some residents simply don't know about them or are reluctant to leave their homes. In Philadelphia, PA, designated block captains check on older residents during heat waves. And cooling centers can be they difficult to access by public transit. ${ }^{x l v}$ A poignant example is in Phoenix, where homeless people rode the air-conditioned light rail to cooling centers to avoid 2017 heat so brutal that it killed 155 people in the city and surrounding areas. ${ }^{\text {xlvi }}$ The city is expected to "spend 2/3rds of the typical year in heat of more than $100^{\circ} \mathrm{F}$ $\left(37^{0} \mathrm{C}\right)$ by the time today's preschoolers are drawing a pension...a climate change and planning professor...states 'The fact is, there's not going to be enough refuge for everybody.", xlvii

"If communities do not take preventative measures, the projected increase in heat-related deaths by the end of this century would be roughly equivalent to the number of Americans killed annually in auto accidents." "xviii To be more specific, "During 2006-2010, about 2,000 U.S. residents died each year from weather-related causes. About $31 \%$ of these deaths were attributed to exposure to excessive natural heat, heat stroke, sun stroke...6\% were attributed to floods, storms, or lightning." "xlix It must be observed that cold weather was indirectly responsible for $63 \%$ of weather-related deaths, but in this case the hypothermic effect is less often a specific event, such as a cold wave. These winter deaths are actually diminished by UHIs, which is perhaps the ${ }^{\mathrm{i}} \mathrm{r}$ only direct benefit, along with more comfortable winter temperatures. ${ }^{\text {I }}$

Even though mortality from heat is highly episodic, heat waves already kill an estimated 12,000 people annually across the world. "The July-August 2010 heat wave in western Russia killed about 54,000 people...from 1981 to 2010, the average American experienced about four dangerously hot and humid days, with wet-bulb temperatures exceeding $80^{\circ} \mathrm{F}$. By 2030, that level is expected to more than double, to about 10 days per summer." "lii In 1995, the American Midwest was hit by a monstrous heat wave that ruined crops and killed over 700 people in roasting cities, which was seven times more than would later die in New York and New Jersey as a result of Superstorm Sandy. Excruciatingly hot summers - the kind that were rare in the 1950s - have become commonplace. The famous climatologist Dr. James 
Hansen and two colleagues have compared actual summer temperatures for each decade since the 1980s to a fixed baseline average: "During the base period, 1951 to 1980 , about a third of local summer temperatures across the Northern Hemisphere were in what they called a 'near average' or normal range. A third were considered cold; a third were hot...Between 2005 and 2015, two-thirds of values were in the hot category, and nearly $15 \%$ were in a new category: extremely hot. Practically, that means most summers are now either hot or extremely hot compared with the mid-20th century." "liii

Cities in hot, humid tropical climates are being increasingly hard hit with the sickening and deadly combination of higher temperatures and more humidity. "Those facing the greatest risk live in the wet tropics, where only slight increases in average temperatures or humidity can result in deaths. However, heat can be deadly even at moderate temperatures of less than $86^{\circ} \mathrm{F}$ $\left(30^{\circ} \mathrm{C}\right)$ if it's combined with very high humidity..." liv South Asia, where one in five of the world's people dwell, could face summer heat waves that are impossible to survive without protection. Hardest hit regions are likely to be in northern India, Bangladesh, and southern Pakistan, with a combined population of 1.5 billion people, many of whom are very poor. Many are dependent on subsistence farming that requires long hours of hard outdoor labor. "A 2015 heat wave that killed at least 3,500 in India and Pakistan saw wet-bulb temperatures around $122^{0} \mathrm{~F}\left(45^{\circ} \mathrm{C}\right)$. A similar wet-bulb temperature was reached during the 1995 Chicago heat wave. Currently about $2 \%$ of the Indian population gets exposed to extremes of $32^{0} \mathrm{C}$ wet-bulb temperatures. According to (one) study, without carbon emissions cuts that will increase to about 70 percent of the population by 2100. ."lv

The Middle East is a hot, arid region that is also very vulnerable to extreme heat. Some towns on the coast of the Persian Gulf have already experienced temperatures of $150^{\circ} \mathrm{F}\left(65^{\circ} \mathrm{C}\right)$ ! They are on their way to becoming uninhabitable. The average water temperature in the Gulf itself is now $90^{\circ} \mathrm{F}$. For comparison, the Caribbean Sea, one of the hottest parts of the Atlantic Ocean, averages $82^{\circ} \mathrm{F}$ $\left(28^{\circ} \mathrm{C}\right)$. The Middle East is getting even more arid, and with less rainfall predicted, the average yield on a number of grain crops is predicted to drop by about $30 \%$ by 2050 . lvi CC has already played a destabilizing role, with a three-year drought in Syria sending farmers to its cities, where insufficient jobs resulted in political unrest and ultimately contributed to the long civil war. The number of Middle Easterners seeking refuge in Europe is sure to mount ever-higher as CC drives more farm families from their parched and strife-ridden land.

More information on heat waves has been recorded, researched and written about than on UHIs. The overlap is clearer and the literature is getting more alarming. The web portal Carbon Brief identified 138 peer-reviewed papers, covering 144 weather events. "Of 48 heatwaves, 41 contained humankind's imprint on the data." lvii The heatwaves that swept America in the summer of 2018 put 100 million people under official heat warnings. "It caused power cuts in California where temperatures in places such as Palm Springs approached $122^{\circ} \mathrm{F}\left(50^{\circ} \mathrm{C}\right)$ and resulted in deaths from New York to the Mexican border." lviii The 2018 heat waves set many records: maximum temperatures were recorded in Norway, Sweden, Japan, California and Montreal, Canada, to name some examples. As Delhi, India is expected to grow by $10 \mathrm{M}$ to a metro population of over $36 \mathrm{M}$ by 2030 , ${ }^{\text {lix }}$ it will get even more extreme heat. "Heat waves in the North China Plain - China's breadbasket - are predicted to become so severe, they would 'limit habitability in the most populous region of the most populous country on Earth...' The big picture: Such heat waves could both threaten lives and dampen economic output in the region, where 400 million people live."

The flip side of this grim issue is that air-conditioning can be an essential adaptation tactic, and arguably a human right in very hot, humid climates, especially in mosquito-infested places where natural ventilation tends to be problematic. In countries without widespread mechanical cooling, deaths rise more sharply during the hottest days. One study estimated that heat deaths in India increase by $3.2 \%$ for every $1.8^{0}$ above $68^{0} \mathrm{~F}$ (every $1^{0}$ above $20^{\circ} \mathrm{C}$ ). Energy use in many countries may rise sharply as people struggle to adapt to a hotter climate." lxi This increased use of energy will only serve to aggravate extreme heat.

Climatologists state that estimating the probability of the recurrence of heat waves is possible. One group of climate scientists "concluded that human activity has more than doubled the probability of experiencing an even worse heat wave than the one that gripped Europe in 2003. Another group concluded that the probability was greater than $95 \%$ that a 2003-like heat wave has 'more than doubled...in spring and autumn, while for summer it is extremely likely the probability has at least quadrupled.", "xii The final death toll in the 2003 Europe-wide heat wave is thought to be around 70,000, a sobering reminder of the health challenge of combined UHIs and CC. Temperatures that used to be seen as outliers - like those in summer 2003 - will become "the norm for summer" after 2060, said Jean Jouzel, former Vice Chairman of the IPCC in 2007 when it won the Nobel Prize. Occasional heat waves could push temperatures in Europe toward $120^{\circ} \mathrm{F}$ unless there is a substantial slowdown in global-warming trends, he said. ${ }^{\text {lxii }}$ "Another team of researchers examined 1,949 deadly heat waves from around the world since 1980 to look for trends, define when heat is so severe it kills, and forecast the future. They found that nearly one in three people now experience 20 days a year when the heat reaches deadly levels. But the study predicts that up to three in four people worldwide will endure that kind of heat by the end of the century..."xiv A 2016 Columbia University study projected that by 2080, 
up to 3,300 New Yorkers could die each year from intense heat made worse by climate change. ${ }^{\mathrm{lxv}}$

Not all UHIs are the same. For starters, the bigger and denser the city the more intense the differential between city and rural air and surface temperatures. UHIs depend on the local climate and vegetative cover. Much of the focus of this book is on cities in the Global North, with their relatively temperate climates and considerable tree coverage. In all cases the focus is on air temperatures and humidity more than surface temperatures, because the former two factors tend to be a better indicator of discomfort and debilitating heat waves. In these cities, the UHIs peak during the late summer afternoon or evening primarily because there is less shading and evapo-transpiration from vegetation in the city center than in the countryside, as well as more vehicles driving about spewing heat from their tailpipes during the day than later at night. Even though they can be more severe in the evening and night, in most cities air temperatures are still cooler at night than during the day. With the gradual increase in global overheating caused by CC, it suggests more daytime activities are likely to be shifted to after sunset. And the lunch-time siesta may move further north and south of the equator as an effective way to deal with mid-day heat.

Summer nights in the U.S. have warmed at nearly twice the rate of days. ${ }^{\text {lxvi }}$ In Mexico City research indicates that arid cities can have UHIs that peak late at night. ${ }^{\text {Ixvii }}$ There can even be "urban cool islands" during the day and evening. The reason for this reversal is that these cities have more trees and vegetation than the surrounding desert or semi-desert. These plants during the day provide shade and cool the air temperature though evaporation of moisture from their leaves. But these cities stay warmer because the heat absorbed by unshaded buildings and pavements during the sunny day is carried into the night, like a giant thermal flywheel. This thermal momentum can actually be a benefit in arid climates, if the nights are cool and clear, with little water vapor in the air. This combination allows warm urban mass to radiate its heat through the more transparent atmosphere, cooling its buildings and occupants during the night more quickly and fully than in climates with warmer and more humid nights. In addition to this radiative cooling, there can be cooling night breezes that ventilate the buildings.

The centers of metro areas can also be hotter at night because of night-time inversions that dramatically lower air temperatures near the ground in the surrounding countryside (even creating frost in early spring). Inversions are produced in cities by UHI plumes of warmer air over cities that trap cooler air near the ground at night, especially when the air is calm. They affect the time of day or night that UHIs hit their peak intensity. These temperature inversions are weakened by buildings and vehicular traffic, which tend to create more air turbulence within cities. Local weather also has an effect, with more intensity during clear weather that allows greater solar heat gain. Weaker UHIs happen when there is cloud cover, and when wind removes heat more quickly from the city. It's clear that heat islands are complicated by the differing sizes, morphologies, altitudes, terrains and weather patterns of urban areas, as well as the multitude of ways these factors can interact during the annual cycles. An unusual example is San Jose, CA, where a U/C Berkeley study has shown downtown San Jose is in fact cooler than its first ring suburb of strip malls and shopping center, with their parking lots. ${ }^{\text {lxviii }}$ While UHIs tend to display similar characteristics, ultimately each metropolitan area finds its own unique and dynamic balance points and scenarios.

Current research on UHIs focuses primarily on temperate climates in developed countries, despite the fact that almost half of the world's population lives in the tropics. Few studies have focused on tropical climates and even fewer examples exist. The urban context and settlement patterns in cities of the developing world are substantially unlike those found in the usually colder Western countries. Therefore, the strategies applied to cool their cities are not necessarily appropriate for use in tropical cities. Research identifies "urban geometry as one of the most important factors governing outdoor microclimatic conditions in a high-density, tropical climate. Due to rapid urbanization and limited resources for managing the urban planning, many parts of the case-study city Dhaka have grown spontaneously. These...areas, mainly residential, with irregular plot sizes and building heights, were found to have relatively better microclimatic conditions than the contemporary, formal built areas with more uniform building heights and sizes. Significant variation is identified in terms of air temperature, mean radiant temperature and wind speed between the two areas." "xix This research is based on analysis of urban geometry, Computational Fluid Dynamics simulations, statistical analysis of thermal comfort surveys and building energy performance - more of which is needed to link urban design and planning with urban climatology.

As already noted, UHIs are economically costly. A 2017 analysis of almost 1700 cities "shows that the total economic costs of climate change for cities this century could be 2.6 times higher when heat island effects are taken into account...For the worst-off city, losses could reach $10.9 \%$ of GDP by the end of the century, compared with a global average of 5.6\%. (For comparison's sake, that's almost double New York City's 2017 budget, and more than China has been recently spending on national defense.) This effect is expected to add a further two degrees to global warming estimates for the most populated cities by 2050." ${ }^{\text {, } x x}$ Hotter temperatures hurt an economy in several ways: more energy is used for electric fans and especially for air conditioners, air is more polluted, water quality suffers and workers are less 
productive. The research team carried out a cost-benefit analysis of various local UHI strategies, such as cool pavements, cool roofs and green roofs, and expanding vegetation in cities. The cheapest measure turned out to be a moderate-scale installation of lighter colored pavements and roofs. Changing $20 \%$ of a city's roofs and half of its pavements to brighter surfaces could save up to 12 times as much they cost to install and maintain, while reducing air temperatures by about $0.8^{0} \mathrm{C}$. ${ }^{\text {xxi }}$ This is a high return for almost any type of investment, especially in buildings and infrastructure. A paper by MIT scholars offers some encouraging news on both the economic and health front: China will largely or even fully offset the costs of its climate initiatives with avoided mortality. ${ }^{\text {Ixxii }}$

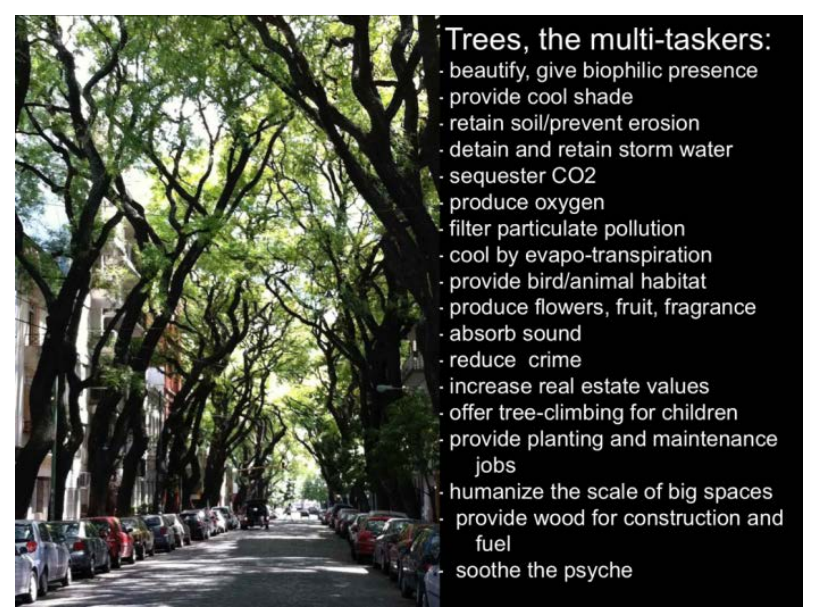

Figure 5. Street trees are stalwart foot soldiers in cooling and beautifying the city, which in turn attract and retain urban residents. Coupled with cool roofs and pavements, they can reduce a city's ambient air temperatures by $4^{0}-9^{0} \mathrm{~F}\left(2.2^{0}-5^{0} \mathrm{C}\right)$ during summer months.[75] Taken together trees are an immense breathing system for the earth that is essential for both plants and animals, including humans. Trees breathe out what we breathe in; we breathe out what trees breathe in; we inter-breathe with trees. (photo by author) Trees are the great natural multi-taskers of the urban environment, remarkable in so many ways.

The arboreal gifts continue: "Even when a tree dies, it continues to give life. First it nourishes insects that bore into its wood and birds that eat them. Eventually it falls, rots, and becomes a seed bed for new trees and plants..."lxxiii Urban trees are like little hospitals, doing so much to enhance micro-climates and to make us feel better psychologically and physically. They've long been appreciated as urban amenities and oases. Indeed, 17th Century Amsterdam's City Council mandated the planting of trees for "sweet air, adornment and pleasantness.", "lxiv Rarely do so many virtues line up on one side of an equation. The earth needs trees. Humans need trees. Cities need trees. What wonderful luck that trees are a primary way to address the planet's overheating cities. Along with reduced waste heat, brighter pavements and rooftops, and better ventilated urban canyons, cities can be healthier, resilient to extreme heat, and more livable.

\section{REFERENCES}

[1] Climate Science Special Report, U.S. Global Change Research Program, ibid

[2] Rob Monroe, “What Does 400 ppm Look Like?” Scripps Institution of Oceanography, 12/3/13

[3] Sarah Zielinski, "Why the City Is (Usually) Hotter than the Countryside,”@SmithsonianMag on Twitter smithsonian.c om, $7 / 9 / 14$

[4] Benjamin Barber, Jihad vs. Mc World, ”1995

[5] Ashifa Kassam, “Canada's 'us and them cities': data shows that most homes are too small - or too big," The Guardian, $5 / 27 / 17$

[6] Several sources make this claim, but some claim that heat waves only are the \#1 killer among natural disasters.

[7] Steven Leahy, "By 2100, Deadly Heat May Threaten Majority of Humankind,” Nat Geo, 6/19/17

[8] Joyce Rosenthal, "Evaluating the impact of the urban heat island on public health: Spatial and social determinants of heat-related mortality in New York City,” Ph.D. dissertation, Columbia University, 2010

[9] Eric Klinenberg, Heat Wave: A Social Autopsy of Disaster in Chicago, 2002

[10] Steven Leavy, "Parts of Asia May Be Too Hot for People by 2100,"National Geographic, 8/2/17

[11] Raven, J. et al., ibid, p. 145

[12] Karen Seto and Shobhakar Dhakal, "Human Settlements, Infrastructure and Spatial Planning," Chapter 12, IPCC 2014 Mitigation, p. 927

[13] Ibid, p. 137

[14] Ibid, p. 144

[15] M. Kimmelman, "Mexico City, Parched and Sinking, Faces a Water Crisis,” NY Times, 2/17/17

[16] David Wallace, ibid

[17] Brian Stone, Jason Vargo, Dana Habeeb, "Managing climate change in cities: Will climate action plans work?” Landscape and Urban Planning 107, 2012, pp. 263-271

[18] Confirmed in email exchanges with Brian Stone in mid-April, 2017

[19] The Weather Channel, 12/9/17

[20] Gerald Mills, "Explainer: Why are cities warmer than the countryside,” citiscope, 1/26/16

[21] Ibid, p. 6

[22] Cool Cars, Heat Island Group, Berkeley Labs (https://heatisland.lbl.gov/coolscience/cool-cars)

[23] “Q and A, Hot Cars,”NY Times, 11/8/17

[24] Joao Medeiros, "The science of why heatwaves are so dangerous to human health,” wired,7/22/18

[25] Oliver Milman, “'It can’t get much hotter ... can it?' How 
heat became a national US problem," The Guardian, $7 / 14 / 18$

[26] David Wallace Wells, ibid

[27] Ibid, paraphrasing from pp. 40-42

[28] “Increased Use of Air Conditioning," Indoor Air Quality, Berkeley Lab website

[29] Marilyn McKenna, "Why the Menace of Mosquitoes Will Only Get Worse” NY Times Magazine, 4/20/17

[30] Scott Campbell, "Unsustainability as a Chronic, Manageable Disease? Alternatives to Sustainability-as-Equilibrium," ACSA Conference, October, 2015

[31] James Temple, "Global Warming May Harm Children for Life,” MIT Technology Review, 12/4/17

[32] Ibid

[33] Niall McCarthy, “The World’s Top Cities for Sustainable Public Transport,” Forbes, 10/30/17

[34] based on conversation and email exchanges with Prof. Edward Ng, Chinese University of Hong Kong, February, 2017

[35] Justin Gillis, "An Effect of Climate Change That You Could Really Lose Sleep Over,“ NY Times, 5/26/17

[36] Dana Nuccitella, "Switching to electric cars is key to fixing America's 'critically insufficient' climate policies," The Guardian, 1/22/18

[37] Andrew Freedman, "The huge challenge of cooling a warming world,” Axios, 7/16/18

[38] Justine Calma, “Heat Check,” Grist, 7/11/18

[39] Ted C. Fishman, “The Shape of Water,” Chicago Magazine, April 2018

[40] Gerald Mills, Ibid

[41] Brian Stone, The City and the Coming Climate, 2012, pp. 93-95

[42] Alan H. Lockwood, M.D., Heat Advisory, 2016, p. 46

[43] Ethan D Coffel et al., "Temperature and humidity based projections of a rapid rise in global heat stress exposure during the 21st century,” IOP Science, 12/22/17

[44] “The long hot summer,” The Economist, 7/28/18

[45] Chilling Prospects: Providing Sustainable Cooling for All, ibid

[46] Ibid, p. 1-15

[47] Brad Plumer, "Really Big Ideas To Beat The Heat,” NY Times, 8/9/18

[48] Anita Snow, "'Urban island effect' compounds Phoenix's sweltering heat,” Chicago Tribune, 7/30/18

[49] Oliver Milman, ibid

[50] B. Plumer and N. Popovich, "As Climate Changes, Southern States Will Suffer More Than Others,” NY Times, 6/29/17
[51] Jeffrey Berko et al., "Deaths Attributed to Heat, Cold, and Other Weather Events in the United States, 2006-2010," National Health Statistical Reports, July 30, 2014

[52] “Beware: Winter is Coming,” New York Times, 12/20/16

[53] Chilling Prospects: Providing Sustainable Cooling for All, ibid

[54] New York Times, 6/6/15

[55] Nadja Popovich and Adam Pearce, "It's Not Your Imagination. Summers Are Getting Hotter," NY Times, $7 / 28 / 17$

[56] Steven Leahy, ibid

[57] Steven Leavy, "Parts of Asia May Be Too Hot for People by 2100,"National Geographic, 8/2/17

[58] Juan Cole, Professor of History, University of Michigan, talk at Science Cafe, Ann Arbor, 10/4/17

[59] The Economist, ibid

[60] Oliver Milman, ibid

[61] Susan Goldberg, “A Talk with Michael Bloomberg,” National Geographic, February, 20181

[62] Andrew Freeman, "China may be most at risk for deadly, extreme heat waves," Axios, 8/2/18

[63] B. Plumer and N. Popovich, "95-Degree Days: How Extreme Heat Could Spread Across the World,” NY Times, $6 / 22 / 17$

[64] Alan H. Lockwood, M.D., Heat Advisory, 2016, p. 48-49

[65] Alissa J. Rubin, "Europe gets a scorching preview of how climate change will affect the continent," Seattle Times, $8 / 4 / 18$

[66] "DoE head displays willful ignorance while killer heat waves broil the southwest," DarkSide, 6/24/17

[67] Justine Calma, ibid

[68] K. Pierre-Louis and N. Popovich, "Nights Are Warming Faster Than Days. Here's Why That's Dangerous," NY Times, 6/11/18

[69] Yu Yan Cui and Benjamin de Foy, "Seasonal Variations of the Urban Heat Island at the Surface and the Near-Surface and Reductions due to Urban Vegetation in Mexico City," Journal of Applied Meteorology, May, 2012

[70] Professor Harrison Fraker, personal conversation prior to the report's publication, $8 / 4 / 18$

[71] Tania Sharmin, "Urban Form and Microclimate: Impacts on outdoor thermal comfort and building energy performance in a high-density tropical context,” Department of Architecture, Cambridge University, April, 2017

[72] "Heat island' effect could double climate change costs for world's cities,” http://www.sussex.ac.uk/broadcast/read/404 $29,5 / 29 / 17$

[73] Ibid

[74] "Research: China's CO2 push will pay for itself, Axios, $4 / 25 / 18$ 
[75] Cool Cities, ibid

[76] Gabriel Popkin, "What the death of an oak tree teaches us about mortality, Aeon, 12/6/16

[77] Jonathan Rose, The Well-Tempered City, 2016, p.87

i Climate Science Special Report, U.S. Global Change Research Program, ibid

ii Rob Monroe, “What Does 400 ppm Look Like?” Scripps Institution of Oceanography, 12/3/13

iii Sarah Zielinski, "Why the City Is (Usually) Hotter than the Countryside,”@SmithsonianMag on Twitter smithsonian.com, 7/9/14 iv Barber, ibid

v Ashifa Kassam, “Canada's 'us and them cities': data shows that most homes are too small - or too big," The Guardian, 5/27/17

vi Several sources make this claim, but some claim that heat waves only are the \#1 killer among natural disasters.

vii Steven Leahy, "By 2100, Deadly Heat May Threaten Majority of Humankind," Nat Geo, 6/19/17

viii Joyce Rosenthal, "Evaluating the impact of the urban heat island on public health: Spatial and social determinants of heat-related mortality in New York City,” Ph.D. dissertation, Columbia University, 2010 ix Eric Klinenberg, Heat Wave: A Social Autopsy of Disaster in Chicago, 2002

x Steven Leavy, "Parts of Asia May Be Too Hot for People by 2100,"National Geographic, 8/2/17

xi Raven, J. et al., ibid, p. 145

xii Karen Seto and Shobhakar Dhakal, "Human Settlements, Infrastructure and Spatial Planning,” Chapter 12, IPCC 2014 Mitigation, p. 927

xiii Ibid, p. 137

xiv Ibid, p. 144

xv M. Kimmelman, "Mexico City, Parched and Sinking, Faces a Water Crisis," NY Times, 2/17/17

xvi David Wallace, ibid

xvii Confirmed in email exchanges with Brian Stone in mid-April, 2017

xviii The Weather Channel, 12/9/17

xix Gerald Mills, "Explainer: Why are cities warmer than the countryside," citiscope, $1 / 26 / 16$

xx T.R. Oke, I.D. Stewart, “Local Climate Zones,” Bulletin of American Meteorology, Soc.93, 2012

xxi Cool Cars, Heat Island Group, Berkeley Labs (https://heatisland.lbl.gov/coolscience/cool-cars)

xxii "Q $\mathrm{Q}$ and A, Hot Cars," NY Times, 11/8/17

xxiii Joao Medeiros, "The science of why heatwaves are so dangerous to human health," wired, 7/22/18

xxiv Oliver Milman, “'It can’t get much hotter ... can it?' How heat became a national US problem,” The Guardian, 7/14/18

xxv David Wallace Wells, ibid

xxvi Ibid, paraphrasing from pp. 40-42

xxvii “Increased Use of Air Conditioning,” Indoor Air Quality, Berkeley $\mathrm{Lab}$ website

xxviii Marilyn McKenna, "Why the Menace of Mosquitoes Will Only Get Worse” NY Times Magazine, 4/20/17

xxix Scott Campbell, "Unsustainability as a Chronic, Manageable Disease? Alternatives to Sustainability-as-Equilibrium,” ACSA Conference, October, 2015

xxx James Temple, “Global Warming May Harm Children for Life,” MIT Technology Review, 12/4/17

xxxi Ibid

xxxii Niall McCarthy, “The World's Top Cities for Sustainable Public Transport," Forbes, 10/30/17

xxxiii based on conversation and email exchanges with Prof. Edward Ng, Chinese University of Hong Kong, February, 2017

xxxiv Justin Gillis, "An Effect of Climate Change That You Could Really Lose Sleep Over,” NY Times, 5/26/17

xxxv Dana Nuccitella, "Switching to electric cars is key to fixing America's 'critically insufficient' climate policies,” The Guardian, $1 / 22 / 18$

xxxvi Andrew Freedman, "The huge challenge of cooling a warming world," Axios, 7/16/18

xxxvii Justine Calma, “Heat Check,” Grist, 7/11/18

xxxviii Ted C. Fishman, "The Shape of Water," Chicago Magazine, April 2018

xxxix Gerald Mills, Ibid

xl Brian Stone, The City and the Coming Climate, 2012, pp. 93-95

xli Alan H. Lockwood, M.D., Heat Advisory, 2016, p. 46

xlii Ethan D Coffel et al., "Temperature and humidity based projections of a rapid rise in global heat stress exposure during the 21st century," IOP Science, 12/22/17

xliii Chilling Prospects: Providing Sustainable Cooling for All, ibid

xliv Ibid, p. 1-15

xlv Brad Plumer, "Really Big Ideas to Beat the Heat,” NY Times, 8/9/18 xlvi Anita Snow, “'Urban island effect' compounds Phoenix's sweltering heat," Chicago Tribune, 7/30/18

xlvii Oliver Milman, “'It can’t get much hotter ... can it?' How heat became a national US problem,” The Guardian, 7/14/18

xlviii B. Plumer and N. Popovich, "As Climate Changes, Southern States Will Suffer More Than Others,” NY Times, 6/29/17

xlix Jeffrey Berko et al., "Deaths Attributed to Heat, Cold, and Other Weather Events in the United States, 2006-2010," National Health Statistical Reports, July 30, 2014

l "Beware: Winter is Coming," New York Times, 12/20/16

li Chilling Prospects: Providing Sustainable Cooling for All, ibid lii New York Times, 6/6/15

liii Nadja Popovich and Adam Pearce, "It's Not Your Imagination. Summers Are Getting Hotter," NY Times, 7/28/17

liv Steven Leahy, ibid

lv Steven Leavy, "Parts of Asia May Be Too Hot for People by 2100,"National Geographic, 8/2/17

lvi Juan Cole, Professor of History, University of Michigan, talk at Science Cafe, Ann Arbor, 10/4/17

lvii The Economist, ibid

lviii Oliver Milman, ibid

lix Susan Goldberg, “A Talk with Michael Bloomberg," National Geographic, February, 2018l

lx Andrew Freeman, "China may be most at risk for deadly, extreme heat waves,” Axios, 8/2/18

lxi B. Plumer and N. Popovich, "95-Degree Days: How Extreme Heat Could Spread Across the World,” NY Times, 6/22/17

lxii Alan H. Lockwood, M.D., Heat Advisory, 2016, p. 48-49

lxiii Alissa J. Rubin, "Europe gets a scorching preview of how climate change will affect the continent," Seattle Times, 8/4/18

lxiv "DoE head displays willful ignorance while killer heat waves broil the southwest,” DarkSide,6/24/17

lxv Justine Calma, ibid

lxvi K. Pierre-Louis and N. Popovich, "Nights Are Warming Faster Than Days. Here's Why That's Dangerous,” NY Times, 6/11/18

lxvii Yu Yan Cui and Benjamin de Foy, "Seasonal Variations of the Urban Heat Island at the Surface and the Near-Surface and Reductions due to Urban Vegetation in Mexico City,” Journal of Applied Meteorology, May, 2012

lxviii Professor Harrison Fraker, personal conversation prior to the report's publication, $8 / 4 / 18$

lxix Tania Sharmin, "Urban Form and Microclimate: Impacts on outdoor thermal comfort and building energy performance in a high-density tropical context,” Department of Architecture, Cambridge University, April, 2017

lxx "Heat island' effect could double climate change costs for world's cities,” http://www.sussex.ac.uk/broadcast/read/40429, 5/29/17

lxxi Ibid

lxxii “Research: China's CO2 push will pay for itself, Axios, 4/25/18

lxxiii Gabriel Popkin, "What the death of an oak tree teaches us about mortality, Aeon, 12/6/16

lxxiv Jonathan Rose, The Well-Tempered City, 2016, p.87 